\title{
FOTOGRAFIAS COM CORPO E ALMA...
}

KOUTSOUKOS, Sandra Sofia Machado. Negros no estúdio do fotógrafo: Brasil, segunda metade do século XIX. Campinas: Editora da Unicamp, 2010. 357p.

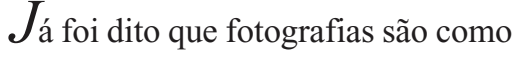
fantasmas, pois são

condensação de tempos, nunca estão inteiramente no passado ou no presente. São seres que habitam o limiar entre o passado e presente, entre vivo e morto, exatamente como os fantasmas [...] Estão aqui e agora conosco e, no mesmo tempo, nos fornecem o testemunho da nossa irremediável diferença em relação ao que foi. ${ }^{1}$

Instigante pensar que o testemunho de uma experiência vivida retorna do passado como seu espectro, como algo ou alguém que nos lembra quem fomos, que nos rememora vivências e modos de ser que foram esquecidos ou, propositadamente, apagados pelos trabalhos de enquadramento de memória.

\footnotetext{
1 Maurício Lissovsky, "Dez proposições acerca do futuro da fotografia", FACOM: Revista de Comunicação e Marketing da FAAP, n. 23 (2011), p. 9
}

As fotografias servem como documentos para atestar a existência de um passado vivido, mas o fazem por meio de certa linguagem e por ações codificadas. São, portanto, monumentos que projetam a autoimagem de uma sociedade a ser perenizada para a posteridade. Fotografias são, ao mesmo tempo, documentos e monumentos, importantes suportes de relações sociais. ${ }^{2} E$ neste registro teórico que o trabalho de Sandra Koutsoukos se inscreve.

A obra de Koutsoukos se divide em uma apresentação, três capítulos, um epílogo, um álbum de fotografias numeradas e devidamente relacionadas no corpo dos capítulos. A composição destes guarda uma autonomia anunciada pela autora na sua apresentação (p. 20). Em cada um se busca

\footnotetext{
Ana Maria Mauad, Poses e flagrantes: ensaios sobre história e fotografias, Niterói: Eduff, 2008.
} 
responder a questões colocadas ao passado que só poderiam ser respondidas por meio das fotografias. Questiona-se, fundamentalmente, o papel desempenhado na dinâmica social pela presença de negros em estúdios de fotógrafos, todos brancos, salvo raríssimas exceções ainda não devidamente documentadas. A própria autora, com estilo claro e direto de apresentar as suas hipóteses de trabalho, leva o leitor a imaginar as múltiplas possibilidades que a prática fotográfica poderia assumir, embora sem uma comprovação factual específica (como é o caso do fotógrafo da galeria dos condenados estudado no terceiro capítulo da obra).

Colocada essa questão fundamental, aliás, bem apresentada no título e na imagem da capa, Koutsoukos orienta o leitor, no primeiro capítulo, num passeio pelos ateliês fotográficos do Brasil oitocentista, considerando o circuito social completo da imagem, ou seja, produção, circulação, consumo e o seu agenciamento pela memória histórica. Neste capítulo, intitulado "A fotografia no Brasil do século XIX”, a autora utiliza bibliografia nacional e internacional atualizada sobre o tema, bem como fontes primárias, com destaque para anúncios de jornais publicados em várias cidades, principalmente os da Corte, São Paulo e Campinas; problematiza o aprendizado do ofício de fotógrafo e o acesso às novidades e inovações estrangeiras no Bra- sil da época; avalia a experiência estética realizada nos estúdios fotográficos por meio da negociação da pose entre fotógrafo e retratado, bem como todos os artifícios para a mise-en-scène adequada à construção da autoimagem aristocrática do Brasil imperial; e finaliza o capítulo com uma breve apresentação dos álbuns de família, verdadeiros reservatórios da memória histórica desse período, e as estratégias de colecionismo associadas a esses artefatos.

Koutsoukos constata a inexistência de álbuns de famílias negras, mas não descarta a possibilidade dessa prática ter existido também entre elas. A forma de guarda das fotografias em arquivos e pelos colecionadores pode ter de fato desmembrado conjuntos importantes de registros familiares de afro-brasileiros que buscassem também a sua monumentalização. No entanto, o agenciamento da memória e suas formas de enquadramento e, neste caso, de reenquadramento, reordenam, sob uma nova lógica, os registros do passado. Há, portanto, que se estudar a presença negra em arquivos de não negros para entender a lógica de organização dos registros visuais sobre a escravidão e o pós-Abolição no Brasil. ${ }^{3}$

\footnotetext{
3 Conforme projeto de pesquisa meu em fase de desenvolvimento, "A presença negra em arquivos de branco: um estudo sobre a representação visual de afrodescendentes em coleções fotográficas", com apoio da FAPERJ, 2011.
} 
Ressalta-se, no primeiro capítulo, a discussão adequada da bibliografia já consagrada na historiografia brasileira e o pertinente diálogo que estabelece com estudos realizados em outras sociedades, notadamente nos Estados Unidos e na França. A importância desse panorama é reconhecida para entender o tema central da obra, embora já tenha sido assunto de estudos específicos e, portanto, cabia ter sido resumido em favor de uma maior ênfase no que se encontra no capítulo dois.

"Entre liberdade e escravidão, a fotografia", é o capítulo central do livro, e por isso mesmo o mais longo. É nele que vemos as relações escravistas, com suas tensões e negociações, reveladas por meio das fotografias. Na ausência de álbuns sobre as famílias escravas, a autora propõe a elaboração de "álbuns imaginados", nos quais se tecem relações sociais diferenciadas no seio da sociedade escravista imperial. Uma tessitura que tem como fio condutor a questão: "qual o motivo de uma pessoa (negra) da segunda metade do século XIX se fazer retratar?" (p.89). A autora apoia a análise das imagens fotográficas na discussão que a historiografia sobre escravidão desenvolve, desde a década de 1980, sobre ser livre e parecer livre. Realiza um breve balanço da situação das diferentes categorias (negros livres, forros e escravos), mobilizando elementos para poder compreender as mensagens transmitidas pelas fotografias.

O primeiro tipo de álbum evidencia a relação entre liberdade e escravidão através dos jogos de representação próprios do retrato fotográfico. Negros livres, forros e escravos negociam sua condição humana no estúdio fotográfico, a moeda é a pose e a miseen-scène do estúdio fotográfico. Os negros livres e forros procuravam a sua dignidade negociando com o mundo branco os signos da sua identidade livre, e com base nessa premissa a autora analisa os retratos dispostos no "álbum de fotografia" apresentado no final do volume. Para cada imagem é narrada uma história que se apoia ora na imaginação fundamentada em premissas históricas (pp. 97-98), ora em indícios documentais extrafotográficos (pp.99-100).

Como garrafas jogadas ao mar que nos chegam do passado, as mensagens contidas nos retratos nos apresentam situações diversas:

\footnotetext{
o rapaz teria sido mandado estudar em boas escolas, quem sabe até enviado à Europa (p.97); o senhor negro idoso vestido com casaca, colete, gravata-borboleta, lenço no bolso da casaca, cartola colocada ao lado de seu dono no chão, bengala à mão e sapatos lustrados (p. 98),
}

foi fotografado de cima para baixo. $\mathrm{O}$ ângulo escolhido pelo fotógrafo denotaria o peso da condição de escravo por toda uma vida, indaga a 
autora? Teria sido resultado de uma negociação entre o fotógrafo e o retratado? (p. 99). Em outra imagem, informações sobre a história da retratada ajudam a desvendar a sua imagem:

Esse é o retrato de Marcellina, a qual era uma ex-escrava, que havia sido libertada pelo seu senhor, seu Antônio, de quem ela era amante. Nessa foto, como deveria, aparece uma mulher bem vestida, bem 'espartilhada', e penteada de acordo com a moda europeia vigente (p.100).

Munida de todos os adereços necessários a uma senhora da boa sociedade, Marcellina, no entanto, não podia esconder sua cor, estigma da escravidão reforçado pelo fato de que a foto foi encontrada no processo instaurado pela esposa de seu Antônio que, sentindo-se lesada pelo marido que gastava o patrimônio familiar para manter o luxo da amante negra na Corte, pediu anulação do matrimônio. Muitos são os relatos de histórias possíveis que as imagens levantam, traduzindo em valores morais e comportamentais as representações visuais do Brasil imperial e escravista.

Um segundo tipo de álbum apresentado neste capítulo é constituído por aqueles que exploram o imaginário do exótico que perpassava as relações de alteridade no século XIX. Como nesse registro era tipificado tudo o que não se adequava ao universo branco e ocidental, boa parte do universo africano e suas formas de ressignificação em terras brasileiras estava rotulada como exótica. Anunciadas pelos fotógrafos como "typos de pretos", essas imagens eram vendidas a título de souvenir para viajantes em passagem pelo Brasil. Neste item, a autora também explora as possibilidades de encenação do exótico no estúdio fotográfico, destacando os usos científicos dessas imagens segundo os protocolos de representação de ideias racistas voltadas para a comparação e hierarquização de diferentes "raças"; e os usos pitorescos, voltados para a construção de um ideal de representação onde o que é próprio de cada lugar entra no registro do típico e curioso.

Nesta série, tal como na anterior, relatos imaginados ou comprovados acompanham a análise dos retratos permitindo, por meio dessa estratégia metodológica, que os retratados adquiram uma personalidade, ou ainda, corpo e alma. Deixam de ser fantasmas da máquina para serem sujeitos que criam histórias, que se apresentam diante da câmera na sua condição de protagonista social, portando elementos de sua etnia, sejam escarificações no rosto, panos coloridos ou adereços variados. Dessa forma, explicitam a sua identidade e atestam uma dignidade por meio da negociação de uma representação negra em estúdio de branco. Mesmo quando esse indivíduo escravizado 
está despojado de suas vestes e tratado como objeto de escrutínio científico, resta-lhe um olhar e a sua expressão corporal de ser humano (fotos 49-53). Sobre essas fotografias, Koutsoukos destaca: "o que interessava ao profissional era o 'olhar científico’ [...] Mas o que interessa aqui é exatamente o modelo" (p.133). Assim, sua análise persegue o que Barthes chamou de noema da foto, ou seja, aquilo que é inescapável ao olhar e sintetiza todo o conjunto, o traço inimitável da fotografia de negros em um mundo de brancos: a escravidão.

O terceiro e último "álbum imaginário" que compõe o capítulo 2 é composto por retratos de amas, destacado pela autora devido a sua grande incidência:

grande parte das fotos que vi de escravos levados pelos senhores aos estúdios dos fotógrafos na segunda metade do século XIX é de amas negras com crianças brancas por elas amamentadas e/ou cuidadas (p.136).

Nesta parte, como em outras situações no livro, a autora assume os riscos de imputar a posição de escravo a um retratado na foto por meio de indícios que atestam essa condição.

As imagens que compõem esse “álbum imaginário" são as que revelam a proximidade dos corpos e a convivência cotidiana entre brancos e negros. Uma convivência marcada por sentimentos contraditórios, como por exemplo, o de ter de largar seu filho para alimentar o filho de outra que acaba sendo criado por quem o alimenta. Na análise destaca-se o retrato da escrava Monica acompanhada do menino por ela criado, que integra a coleção Francisco Rodrigues, pertencente ao acervo da Fundação Joaquim Nabuco, em Recife, já famosa por ter sido reproduzida em diferentes publicações. Koutsoukos segue a trilha da possibilidade histórica, avaliando a imagem como índice de uma relação social que se constitui tanto dentro como fora do estúdio fotográfico: no estúdio, porque Monica não desvia o olhar do fotógrafo e o mira como se quisesse contar a sua história; fora do estúdio, levantase a questão: "Conseguiria ela a sua alforria, fruto do reconhecimento, após tamanha dedicação?" (p.140).

Em busca de respostas, a autora envereda pelo estudo das relações entre amas e senhores através dos anúncios em jornais onde se comprava, vendia, alugava e buscava uma ama. Estuda também a posição científica sobre as amas de leite negras nas teses dos doutores de medicina, onde se critica a suposta falta de higiene desse costume e se recomenda o aleitamento materno. Koutsoukos conclui essa parte, que poderia ser menos extensa, avaliando a questão do afeto na sociedade paternalista, valorizando a perspectiva das sensibilidades sociais.

Apresentadas as condições his- 
tóricas em que se desenrolaram as relações entre amas, senhores e crianças, a autora se volta para a presença das amas no estúdio fotográfico. As fotografias analisadas, no item final do capítulo, revelam as condições de representação de escravos domésticos numa mise-en-scène bastante artificial, mas que, ainda assim, denotam aspectos específicos desse tipo de escravidão. Mais uma vez, Koutsoukos observa atentamente os indícios presentes nas fotos, indicando como as amas se postavam diante da câmera, como seguravam os bebês no colo ou como os cobriam e carregavam com os panos e xales usados pelas diversas nações africanas (p.199).

Entretanto, o que se destaca na análise de Koutsoukos é a busca por transformar retratados em sujeitos, escravos em seres humanos, de carne, osso e alma, como expõe na conclusão do capítulo 2 :

No entanto, o que mais interessa é que as amas, que também não teriam sido levadas aos estúdios desavisadas (algum tipo de negociação certamente acontecera), conseguiram trair a pretensa harmonia daquelas fotos e deram, umas mais e outras menos (é claro), um 'jeito' de participar daquele que também era o seu retrato; as amas também se deram a ver (p. 202).

O capítulo final, intitulado " $\mathrm{Na}$ Casa de Correção da Corte, a 'Galeria de Condenados'”, se debruça so- bre dois álbuns que integram o acervo da Coleção Dona Theresa Christina, constante da Divisão de Manuscritos da Biblioteca Nacional no Rio de Janeiro. Entretanto, antes de iniciar a análise dos álbuns, Koutsoukos abre o capítulo com uma extensa introdução sobre as diferentes formas de identificar criminosos, que vai do registro no próprio corpo do preso, passando pelo retrato falado, pela fotografia até chegar à impressão digital.

O fato dos álbuns terem sido encontrados na coleção doada à Biblioteca Nacional pelo imperador quando do seu exílio, leva a autora a levantar a hipótese - como ela mesma chama atenção, não comprovada - de que ambos tivessem sido encomendados por d. Pedro II para atestar sua benevolência em fornecer indulto a numerosos presos:

não pude descartar a suposição de o objeto álbum ter sido usado e guardado como uma espécie de 'troféu', que atestava a 'magnanimidade' do imperador comutador de penas (p.223).

O capítulo, embora seja mais interessante para a história da prática fotográfica no Brasil do que propriamente para o estudo da escravidão, evidencia que a maioria absoluta dos presos era negra e escrava. Fato por si só relevante para se pensar o que era considerado crime no século XIX, dentro das estratégias de resistência à violência institucionalizada da escravidão. 
Além da parte introdutória, que descreve as práticas de identificação de criminosos no século XIX, o capítulo é composto por mais quatro subcapítulos. No primeiro, a autora apresenta os álbuns do ponto de vista material e arquivístico, identificando o local de guarda, os materiais de sua composição e o formato da apresentação das fotografias nas páginas. Nos seguintes, ela desenvolve um estudo minucioso sobre a organização do serviço de fotografia na Casa de Correção da Corte, por meio da consulta dos relatórios ministeriais, da contabilidade da instituição, da correspondência de seu diretor, entre outros documentos depositados no Arquivo Nacional, e consegue identificar os objetivos do serviço fotográfico, as dificuldades de sua instalação e a precariedade de seu funcionamento, a ponto de identificar que o fotógrafo era ele próprio um preso que assumiu a função, tendo para tanto de se submeter a um árduo aprendizado ( $\mathrm{p}$. 227 e segs.).

Na sequência, a autora desenvolve uma análise sobre os tipos de enquadramento, fundo e pose, destacando o posicionamento dos presos diante da câmera, os aspectos da estética facial e os possíveis adereços e indumentárias entrevistos nas imagens. Como conclusão, escreveu "Uma galeria de histórias" na qual relaciona o que conseguiu levantar sobre os presos fotografados, um ver- dadeiro mar de histórias, nas quais aprendemos que, se o imperador concedia perdão imperial a um preso que era escravo, o perdão da pena o libertava também da escravidão ( $\mathrm{p}$. 246). Por aí também conhecemos a trajetória do negro José Sebastião da Rosa, conhecido nas ruas do centro da Corte como "Juca Rosa", tido como feiticeiro com uma grande clientela feminina, que foi preso por estelionato, cumpriu pena e, depois de solto, tornou-se guarda da municipalidade. Na avaliação da autora: "na foto da 'Galeria', vemos um bonito homem negro, bem penteado, de barba (não apenas um ou outro fio), bigode e rosto franzido" (p. 255). Pelo visto, os encantos de Juca Rosa sobreviveram ao tempo, impregnados à sua imagem. ${ }^{4}$

Por fim, no epílogo do livro, Koutsoukos recupera algumas fotografias já tratadas nos capítulos anteriores como imagens referenciais de uma condição social e que podem ser também trabalhadas por três categorias de análise: retratos de estúdios que denotam a condição social de liberto, forro ou escravo; o registro do exótico, que denota a mercantilização e a objetificação da condição de ser negro, presente nas fotos de souvenir e de documentação 'científica' de viés

\footnotetext{
4 Ver mais sobre este personagem em Gabriela dos Reis Sampaio, Juca Rosa: um pai-de-santo na Corte imperial, Rio de Janeiro: Arquivo Nacional, 2009.
} 
racista; e, por fim, os retratos da "Galeria dos Condenados", em que a situação da tomada da imagem, circunscrita a um estúdio improvisado e feitas por um fotógrafo que era também preso, gera condições específicas para a negociação da pose, com resultados variados, dentre os quais a humanização do retratado.

Interessante pensar como práticas fotográficas diferenciadas evidenciam experiências históricas diversas numa mesma sociedade que denominamos de escravista. $\mathrm{O}$ que nos possibilita indagar se as relações sociais escravistas não seguem também os padrões da representação visual da forma como se revelam nas fotografias, na sua pluralidade de conflitos, confrontos e negociações. Olhar diretamente para o fotógrafo implicaria em encarar o senhor? O negro liberto, ao andar calçado, pavimentava o caminho da liberdade com um signo que o diferenciava do escravo que não devia usar sapato? Amparar a criança que não é sua com o pano da Costa seria identificar como seu algo que não lhe pertence? Enfim, perguntas que à historiografia não tinham sido feitas porque as imagens ainda eram opacas.

O livro de Sandra Koutsoukos ainda possui outros importantes atributos, como o de compartilhar com o leitor, em escrita clara e direta, suas hipóteses, dúvidas e indagações. Comprova e atesta por meio de documentação minuciosamente compulsada em arquivos e bibliotecas, ao mesmo tempo em que dá asas à imaginação, ao preencher com possibilidades históricas aquilo que faltou à documentação. Compõe, assim, uma obra densa, que possibilita ao leitor uma rica experiência de leitura.

Em suma, no livro de Koutsoukos a fotografia cumpre o papel fundamental de atestar que a experiência da escravidão oitocentista deixou marcas indeléveis tanto nas superfícies albuminadas dos carte-de-visite, quanto na memória histórica que não deve ser apagada. Daí a atualidade e relevância dessa obra, que contribui para que o passado se faça presente na construção de uma sociedade plural.

Ana Maria Manad anaessus@uol.com.br Universidade Federal Fluminense 